of the corrosion experienced in the Gulf of Paria, where the United British Oilfields of Trinidad, Ltd., reported that a 5/16 in. mild steel plate, forming the bottom of a storage tank, was eaten through in nine months. Among the protective measures discussed, special mention was made of oxide films, not more than 1.6 millionths of an inch in thickness, yet capable of providing an armour, or first line of defence against corrosion.
In most cases of general wastage of steel, the removal of the rolling-mill scale, prior to exposure, had the effect of increasing the amount of corrosion, but, on the other hand, as regards pitting, its influence was almost entirely favourable. The wastage of cast iron was generally very much less than that of the rolled irons and steels, and the pitting in a five-year test was negligible.

Brysson Cunningham.

\title{
Insect Life of Temporary Rain Swamps in British Guiana
}

\author{
By F. A. Squire, Department of Agriculture, British Guiana
}

$\mathrm{T}$ WICE a year, during the months immediately preceding and following the solstices, the lowlying, badly drained grasslands of the coastal belt of British Guiana are converted into temporary swamps by the heavy rains which fall during those periods. This condition naturally varies a good deal in extent and duration, but generally lasts for at least several weeks. In that time the swamps become the home of innumerable insects of diverse species, some of them of the greatest concern to mankind, and all of them very interesting.

The following account is based on observations made during the mid-year rainy season of 1935 . The rains commenced on May 16 and continued with daily precipitations and frequent heavy downpours up to the end of June, when dry spells began to intervene. Up to this point the season was typical, but an opportunity to prolong the investigation was afforded by an unusually wet July and August. The rainfall recorded at the Botanic Gardens, Georgetown, for the months in question was: May, 11.56 in., June, 14.37 in., July, $8 \cdot 12$ in. and August, 13.78 in., totalling 47.83 in. With the cessation of the rains, the swamps drain off and vanish almost as suddenly as they appear, so that there is never any stagnation.

Bearing in mind the abruptness of the onset of the rains, it is perhaps scarcely necessary to labour the point that when these aquatic conditions arise, there is a complete and somewhat sudden change in the savannah population-the dry season dwellers evacuating their territory with a good deal of haste and panic, and often with considerable loss of life. This is quite commonly observed in the case of Solenopsis, the red stinging ant. This notorious insect infests, and often monopolizes, the countryside-especially low-lying grasslands. Here it establishes its colonies in ever-increasing numbers, and it would, in a short time, surely become a terrible scourge but for the blessed ruthlessness of Nature. With the advent of the rains and the flooding of the savannahs, these colonies are promptly inundated. How the ant meets this parlous situation by forming living rafts for the purpose of salvaging the brood and fertile queens is well known. But how many of these castaways ever reach safety, and what is the extent of the subterranean mortality?

Even more disastrous is the effect of the floods on other underground insects, especially the larvæ and pupæ of humous and root-feeding Coleoptera. These frequently have no aquatic adaptations, and are consequently easily overcome by excessive moisture. These inhabitants of the soil have, presumably through natural selection, come to pass their more defenceless stages during the dry seasons. But this arrangement is precarious, for the weather is often capricious, and unseasonable deluges not infrequently occur, creating very unfavourable conditions for the soil fauna. The Dynastids, Dyscinetus geminatus and D. bidentatus, in particular, are very adversely affected, and may be prevented from making their appearance in pestilential numbers for several years by such an occurrence. Tangible evidence of the havoc caused is not lacking, for the receding waters leave behind them innumerable dead grubs scattered over the countryside.

Above the ground another story is told. The rather populous Orthoptera and Hemiptera that may, in dry weather, be swept up from any patch of grass, are better equipped for flight to higher levels; yet many are trapped, and may be seen clinging to a hopeful blade of grass or making sorry efforts to swim with ill-adapted limbs. There is, indeed, one local grasshopper which, I believe, must be unique, whose life is normally passed in semi-aquatic surroundings and whose hind-tibiæ are curiously suited to this element, being flattened and expanded to form paddles. 
The disappearance of the dry season population with the advent of the rains is soon followed by the appearance of a number of bizarre water dwellers, the life of which, for the few weeks of the duration of the swamps, is a fierce internecine war. Among the first to colonize this new environment are the mosquitoes. The females continue to oviposit throughout the season, thus keeping the swamps well supplied with larvæ and pupæ of all ages. Yet this apparently ideal breeding ground is but a death trap for the species. The vast majority never reach maturity, but fall a prey either as larvæ or as pupæ to predacious insects. By far the most numerous species is Culex similis Theo. Also present, though in decidedly fewer numbers, is Urotaenia lowii Theo. Anopheles tarsimaculata Goeldi is found here and there in shady spots.

Chief among the natural enemies of the Culicidæ are dragonfly larvæ, of which about six different species were found. They are the most successful of the swamp fauna. This is due to their great agility, their cryptic patterns, their curious habit of camouflaging themselves with débris when at rest, and perhaps to their repulsive, spidery appearance. That they are not far more predominant is probably due to their deplorable cannibalism. While the young nymphs content themselves with mosquitoes, the larger instars are inclined to disdain this exiguous diet and go for members of their own family, which they disembowel with the movable hooks of their mask. Their cannibalism is, however, facultative; in fact, they have a catholic palate, and their diet includes tadpoles, two species of which swarm in the temporary swamps, young grubs of waterbeetles, tabanid maggots and Belostomatidæ.

It is a noteworthy fact that these Odonata pass through their life-cycle quite comfortably during the short duration of the swamps. It seems that the long life-history ascribed to them in textbooks is largely a laboratory fiction, as they do very poorly in captivity, even when natural conditions are closely simulated.

Two species in particular, Erythrodiplax umbrata Linn. and Leptothemis vesiculosa Fabr. were kept under observation in an aquarium. By far their most striking peculiarity is their habit of camouflaging themselves. They kick up the sediment, which settles in a fine shower on their limbs and body, and covers them like a mantle. In this manner they not only escape the unwelcome attentions of their enemies while resting or during moulting, but are also better able to seize their prey unexpectedly, thus securing an initial advantage in combat which may be sorely needed when the object of their designs is a well-matched nymph or a robust Hydrous grub.
Full-grown larvæ of Hydrous are never attacked, as they would be rather unmanageable, and a discreet preference is shown for harmless fare like tadpoles. These make easy prey, and are simply seized under the jaw and gnawed to pieces without being able to offer any resistance beyond an ineffectual wriggle. With this defenceless pabulum the dragonflies make merry, and for our immunity from at least one of the seven plagues of Egypt we owe a good deal to the Odonata.

In their turn, however, the Odonata are beset by rapacious foes. Among these the most fearsome is the silver water-beetle Hydrous smaragdinous. The adult is an inoffensive vegetarian, so that it is all the more surprising to find the larvæ equipped with a pair of huge crescentic jaws. Dragonfly nymphs, despite their superior agility and cryptic colouring, fall easy prey to these slug-like creatures which, covering themselves with fine mud, and moving slowly but quietly, are able to approach unobserved within striking distance of their quarry. Their favourite food is the tadpole, which is secured in an interesting manner : the tadpole, having the advantage of speed and elusiveness, is first of all rendered hors de combat by being deprived of its tail. In many cases this is accomplished by a single sweep of the great jaws, but where the victim is more robust, the amputation is not quite so artistic.

The life-history of the silver water-beetle is of unusual interest. The egg mass is approximately hemispherical and about $\frac{3}{4}$ in. in diameter. It consists of dry froth, with an outer impermeable crust. The flat side has a hardened, triangular pad which floats vertically with the apex up, and is invariably attached to a straw which serves to camouflage it. The eggs are pale yellow and about $4 \mathrm{~mm}$. in length, and are placed vertically in the side of the hemisphere in a single layer of about three hundred. The rest of the space being taken up by froth, the centre of gravity is low, thus stabilizing the egg mass. More remarkable is the rapidity of the embryology: the eggs are laid within a day or two of mating and are quite undeveloped at oviposition; yet within three days the larvæ emerge. The outer envelope is ruptured round the base of the triangular pad and the grubs swim out. There are three casts, the first taking place two days after eclosion, the second about four days later, and the last before pupation, seventeen days after that. By this time the grub has attained a length of two inches. There is a quiescent prepupal stage of six days, followed by a pupal instar of five days. Thus the total life-cycle occupies about thirty-one days. Another water-beetle with similar biology occurring in the temporary swamps is Tropisternus laevis Sturm. 
Other insects of interest in this association are the Belostomatidæ, of which several species occur. Their prey consists of mosquito, dragonfly and tabanid larvæ, which they seize with their prehensile forelegs.

In conclusion, attention may once more be directed to the rapidity with which the temporary swamps are colonized, and the intense and incessant competition among the colonists and its effect on the mosquito population. The comparative paucity of mosquitoes during the thick of the rains is a common experience in British Guiana, and is generally attributed to the destruction of larvæ by excessive flooding. While there may be something in this, there is little doubt that it is due in a far greater measure to the mosquito's aquatic associates. These are slower at colonizing at the onset of the rains, and cannot establish themselves at all in the ephemeral puddles that result from the intermittent showers towards the end of the season. This suggests a reason for the prevalence of mosquitoes at the beginning and at the end of the rains, and their scarcity when the rainy season is in full swing.

\section{Obituary}

\section{Dr. W. J. S. Lockyer}

$\mathrm{T}$ HE sudden death of Dr. Lockyer has deprived astronomical circles of a familiar and welcome figure. While walking down to his house from the Norman Lockyer Observatory on July 15 he was seen to fall on his face; and when some men close by went to help him up, he was found to be dead. About two years ago he was laid up for several months on account of phlebitis, and his death seems to have been a sequel to this attack.

To all his friends, Dr. William James Stewart Lockyer was affectionately known as 'Jim', and by all of them he will be greatly missed. He was the fifth son of Sir Norman Lockyer and was born on January 3, 1868. His mother died when he was eleven years of age, and the present Lady Lockyer was married to Sir Norman in 1903. The stages of Dr. Lockyer's education at Cheltenham College, Trinity College, Cambridge, the Royal College of Science, South Kensington, and the University of Göttingen, all led naturally to a scientific career and to his carrying on the astronomical studies of his distinguished father. The subject of the thesis for which he received his doctorate at Göttingen in $\mathbf{1 8 9 6}$ was the variable star $\eta$ Aquilæ, all the available observations of which he submitted to full discussion with some interesting conclusions. Among the results obtained was that the epoch of maximum luminosity oscillates to and fro to the extent of five hours on either side, with a period comprising four hundred maxima. The minima are also subject to a similar oscillation, and four secondary undulations were revealed on the curves representing the variability of the star's magnitude, recurring at intervals of forty-three hours, or one-quarter of the main period.

Variability of another kind, namely, that of the spectrum of the star $\gamma$ Cassiopeiiæ, was the subject of Dr. Lockyer's most recent papers to the Royal Astronomical Society. This star has a constant magnitude of $2 \cdot 25$, and its spectrum was also believed to be constant until a close examination of photographs taken by Dr. Lockyer proved it to change in a very peculiar manner. The spectrum contains hydro. gen lines each made up of double emission lines superimposed on a broad absorption line. The two components of each of the double emission lines undergo regular changes of relative intensity; and in his last paper on this star, contributed to the Royal Astronomical Society a little more than a year ago, evidence was presented of some very remarkable variations of this character.

This paper was one of forty dealing with spectroscopic work carried out at the Norman Lockyer Observatory, Sidmouth, since 1920, nearly all of them by Dr. Lockyer himself. The Observatory was founded by Sir Norman with the help of sympathetic friends in 1912, after the decision to transfer to Cambridge the Solar Physics Observatory in which he had carried on astrophysical and astrochemical work continuously since 1875 . It was first called the Hill Observatory, but was given its present name after Sir Norman's death in 1920. Four years earlier, the Norman Lockyer Observatory had been formed into a Corporation under the Companies (Consolidation) Act, 1908, with Sir Robert Mond, who was a school friend of Dr. Lockyer's at Cheltenham College, as chairman. Dr. Lockyer succeeded his father as director of the Observatory in 1920, and though he usually had only one assistant observer, the amount of original work done has been remarkable, with the result that the Observatory now possesses as fine a collection of photographs of stellar spectra as any observatory in Great Britain. Such a record is particularly good for an institution maintained entirely by private benefactors and without any State aid.

Both in association with his father, and separately, Dr. Lockyer took part in a number of total solar eclipse expeditions. Among these were Government expeditions to observe the Vadso (Lapland) eclipse of 1896; Viziadrug (India), 1898; Alicante (Spain), 1900 ; Palma (Majorca), 1905 ; and Vavau (Tonga Islands), 1911, when he was the chief of the expedition. Other eclipses observed by him were those of 1912 (France); 1921 (Scotland); 1927 (England); 